\title{
A Comparison of the Nutritional Outcomes of the Children of Labour Migrants and the Children of Non-Migrants, Based on Height-for-Age Measurements in Kenya
}

\author{
Patricia A. Elung'ata, Shepherd Khondowe and Andy Beke \\ African population and Health Research Center \\ Scientific Officer, Tropical Disease Research Center, Zambia \\ School of Health Systems and Public Health, University of Pretoria, South Africa
}

\begin{abstract}
While much work has been devoted to understanding the causes and broad economic consequences of labour migration, much less has characterized labour migration as a cause of socio-economic inequalities in health. Child malnutrition is one of the most important causes of infant and child mortality in developing countries, with preschool children being particularly vulnerable. It has been estimated that in the sub-Saharan Africa (SSA), the number of underweight children has increased by 8.2 million over the last decade. Traditionally, the remittances migrants return to sending communities are considered an important mechanism for improvements in children's access to education, nutrition and health care. However, migration introduces other constraints to households by allocating most other household responsibilities, including child care and home maintenance, to the remaining parent. The transfer of responsibility and burden may translate directly into a lower level of health inputs provided for children. For this reason, it is not a priori clear that parental labour migration should improve child health. Measuring socio-economic inequalities in a population's health is important because national averages often mask differences within and across sub-groups. For policy purposes it is especially relevant to understand why unfair and avoidable inequalities (or inequities) exist and what actions may be taken to improve equity. Furthermore, such analysis can serve as input to aid in the development of evidence-based policies, and can help programmes to identify the most appropriate mixture of child nutrition interventions. The aim of this paper is to compare the nutritional outcomes of the children of labour migrants, and the children of non-migrants, based on height-for-age measurements. A cross-sectional analytic study design was conducted using data from the Kenya Demographic and Health Survey of 2003. Child health outcomes selected were those that specifically require parental mobility, nutrition, which requires not only money but also time to buy the food, and immunization, which requires travel to medical facilities, were considered in the analysis. Logistic regression was used to identify other independent predictors of stunted growth. From the results, parent migration was not found to have a statistically significant impact on the risk of stunted growth in children. For public health these findings highlight the need to review the scope of health programmes, to include interventions from other sectors such as, agriculture and education. The results show that strategies to address factors contributing to poor health outcomes in children are likely to require collaborative and inter-sectoral actions that are not limited to health authorities or the health system. For Monitoring and evaluation, these findings highlight the need draw on indicators from other sectors during program evaluation.
\end{abstract}

Keywords: Comparison, Nutritional Outcomes, Children, Labour Migrants, Non-Migrants, Height, Age Measurements, Kenya

\subsection{Labour migration}

\section{Introduction}

While much work has been devoted to understanding the causes and broad economic consequences of labour migration, much less has characterized labour migration as a cause of socioeconomic inequalities in health [1].

Traditionally, the remittances migrants return to sending communities are considered an important mechanism for improvements in children's access to education, nutrition, and health care [2],[3],[4]. However, migration introduces other constraints to households by allocating most other household responsibilities, including child care and home maintenance, to the remaining parent [5]. The transfer of responsibility and burden may translate directly into a lower level of health inputs provided for children. Empirical evidence demonstrates that parental migration predicts a smaller probability of children being breast-fed and receiving immunizations [6]. For this reason, it is not a priori clear that parental labour migration should improve child health. 
Measuring socio-economic inequalities in a population's health is important because national averages often mask differences within and across subgroups. For policy purposes it is especially relevant to understand why unfair and avoidable inequalities (or inequities) exist and what actions may be taken to improve equity.

Such analysis can serve as input to aid in the development of evidence-based policies, relevant to the particular context or country, to reduce inequities. For example, decomposition analysis using data from the 2003 Demographic and Health Survey in Mozambique showed that the four biggest contributors to poor growth in children (defined as height-for-age falling 2 standard deviations below the median of the reference population) stratified by household wealth are: source of drinking water $(19 \%)$, household wealth itself $(17 \%)$, geographical differences (16\%) and mother's occupation (13\%). An additional 10 factors identified in the survey together contribute $35 \%$ [7]. Using this technique to uncover inequities reveals that strategies to address factors contributing to poor health outcomes in children are likely to require collaborative and inter-sectoral actions that are not limited to health authorities or the health system.

The United Nations International Children's Fund (UNICEF) framework on malnutrition further highlights the multi-sectoral nature of the causes of child malnutrition [8] Causes are categorized as immediate, underlying and basic. Basic causes of malnutrition include inadequate education, the political and ideological superstructure, the economic structure, and the resource base. These factors influence the underlying causes food, care, and health - which, in turn, directly affect the two primary proximate determinants of nutritional status, and survival namely dietary intake and disease. Since parent labour migration directly affects the economic structure and resource base of households, consequently affecting household food security, and other underlying and immediate causes of malnutrition, it can be categorized as a basic determinant of child malnutrition.

Malnutrition leads to compromised immunity, which results in greater incidence, severity and duration of disease in children. For female children, poor nutrition has an intergenerational component. Children born to malnourished mothers are more likely to be of low birth weight and to die as infants. If these children are female and survive, they are likely to be stunted in adulthood and to give birth to low birth weight babies if something is not done to break the cycle [9].

Understanding the multiple causative factors of child malnutrition can help programmes to identify the most appropriate mixture of child nutrition interventions. In general, child nutrition programmes aim to affect immediate and underlying causes of malnutrition and cut into the vicious cycle of malnutrition-infection, often through a combination of community organization and service delivery interventions. However, since about two-thirds of the income of poor households goes to food, some policies and programmes aimed at improving food access widen their aim to include reducing poverty [8]. Many of the activities needed to improve household food security may be outside the scope of healthy/nutrition programs. Interventions may need to be introduced from several sectors, for example, agriculture, education, and livelihoods.

From a monitoring and evaluation standpoint, nutrition programmes that seek to improve access to food may have to draw on indicators from other sectors during program evaluation, otherwise it may be difficult to establish that observed changes in nutrition outcomes are attributable to a particular intervention. Parent labour migration for example, can be an independent predictor of good nutritional outcomes in children, which if not controlled for during program evaluation, may inflate or deflate the observed changes in the community's nutritional outcomes that can be attributed to a programme.

Internal Migration has historically been seen as both a cause and solution for social inequalities in health. Its effects, however, vary across environmental and individual gradients. Environments are influenced by factors such as the degree and type of industrialization, and the quality of housing. Individual behaviour, however, also contributes to social difference, both through migration and by the effects on the individuals of cultural experiences [10]. Reduction on inequalities may be possible through larger social action. There remains an important role for public health in addressing determinants of health at the population level.

\subsection{Statement of the problem}

Child malnutrition is one of the most important causes of infant and child mortality in developing countries, with preschool children being particularly vulnerable [11]. In 2000, approximately $27 \%$ of the children under 5 years in developing countries were underweight, the number of underweight children had increased by 8.2 million over a period of ten years [12]. The high level of malnutrition in children and women in the sub-Saharan Africa poses a major challenge for child survival and development.

The Kenya Demographic and Health Survey Report (KDHS) shows that child health measured by nutritional status improved only slightly between 1999 and 2003. The improvement was also unequal, with some provinces reporting more malnutrition than others. At the individual level, inadequate or inappropriate feeding patterns may be the cause of this malnutrition but numerous socioeconomic and cultural factors influence the decision on patterns of feeding and nutritional status [13]. 
Labour migration is one such economic factor, whose effect on the health of children is not really known. Empirical findings by Agesa [14], suggest that internal labour migration may result in a household's improved economic well-being. This, however, varies depending on the size of the household. Macours [15] shows that if the socio-economic status of the sending migrant household remains constant as a result of the additional migrant income, child health outcomes will not be affected. Ssengozi [16], however, shows that parent migration explains only a small component of the variance in child survival. From this it is not clear whether labour migration helps to improve or worsen the health of migrant children. The study sought to answer that question by comparing the nutritional status and health-care utilization patterns of the children of migrant parents and those of non-migrant parents using data from the Kenya Demographic and Health Survey of 2003. This was done by assessing the impact of remittances on child health outcomes, the impact of migration on the mobility of the remaining parent and the consequent bearing of this on the health outcomes of the children leftbehind.

\section{Materials and Methods}

Based on the Household and Women questionnaires, a cross-sectional analytic study was conducted to compare the prevalence of stunted growth in children under the age of five years by parent's migration status. The $2003 \mathrm{KDHS}$ collected information on children under the age of five years from a total of 5,949 (weighted) children. Data on the child's age, height, weight, sex and the various vaccinations each child had received were collected. This information, linked with socio-economic and demographic information on the child's mother, formed the dataset for the study.

For inclusion criteria, the study used child data which contained no missing values for the child's age, no missing or don't know values on the vaccinations that the child has received, and information on the parent's migration status. The study excluded child data with missing information on parent's migration status, and data on children of age above 60 months. The study used a sample of 3015 (weighted) children, 51\% of the 5949 (weighted) child sample of the KDHS 2003.

Of the 5949, only 5189 were retained who had their age in months recorded. Using the main explanatory variable ("Does parent work away or at home?"), the author further limited the sample to 3195 children who had this question answered. The study then excluded all children who did not have their heightfor-age standard deviations calculated and recorded in the dataset, and derive a sample of 3040 children. An attempt was made to calculate height-for-age standard deviations, while using mean replacement method to replace the missing values in the child's height, weight, age, and sex. The results found differed greatly from those in the KDHS 2003 dataset. As such, for the purpose of producing a standardized report that could be compared to others written on the KDHS 2003, the study used height-for-age standard deviation values calculated by the Central Bureau of Statistics (CBS) and recorded into the dataset. A final exclusion of children for whom data on the BCG DPT and Polio vaccines except for Polio 0 was recorded as missing or not known, resulted in a sample of 3015 children (51\% of 5949).

The study used a Height-for-Age $Z$ score of $<-2$ SD to define stunted growth. From the sample of 3015 children, 899(29.82\%) were stunted, while 2116(70.18\%) were not stunted. Using the World Health Organization (WHO) cut-off point [17],[18],[19], the author expected to observe complete immunization only for children of age 12 months or older. A combined indicator immunized was constructed, which was set to 1 (one) if the child had received a BCG vaccination, three doses of DPT vaccine, and three doses of polio vaccine (excluding polio 0 : vaccine given at time of birth), and 0 (zero) if the child had missed any of the vaccinations. Based on the indicator, the study derived a sample of $1363(45.21 \%)$ children who were immunized, and $1031(34.20 \%)$ children who were not immunized. The remaining $621(20.60 \%)$ children were less than 12 months old and were not included in the analysis.

The child data used in the study was derived from a dataset provided by MACRO International, which consists of combined data from two questionnaires, the Household Questionnaire and the Women's Questionnaire. The Household Questionnaire was used to capture basic information on household members. For the study, the household data contained information on child's age, gender, height, weight and selected descriptive characteristics of the child's household. The Women's Questionnaire was used to collect information from all women age 15-49 years. The study used women's data containing information on husband's background characteristics, child feeding practices, child immunization and the woman's socio-demographic information.

With respect to variables, a migrant parent was defined using the question: "Does parent work away or at home?" In the KDHS survey of 2003, this question was not administered to the male respondents. The description of migrant parents was, therefore, limited to female parents only. A migrant parents was coded as 1 (one), a non-migrant parent as 0 (zero). To address possible information bias, we include additional explanatory variables in our analysis. These include information on the migrant, the migrant household, and guardian in whose care the migrant's children are left. 
Child health outcomes selected were those that specifically require parental mobility: nutrition, which requires not only money but also time to buy the food, and immunization, which requires travel to medical facilities. Several studies have used these indicators to compare health outcomes among vulnerable child groups in developing countries, within Africa [17],[18],[19], and outside Africa [20],[21].

Nutrition was measured in the children of age 0-59 months on Height-for-age. Children below -2 SD from the median of the NCHS reference population in terms of height-for-age are considered short for his/her age [22],[23] We group the children into two categories, 0 (zero) for no stunted growth, and 1 (one) for stunted growth.

The analysis of immunization coverage was limited to children age 1-4 years. A child was defined as fully immunized if he or she had received a BCG vaccination, three doses of DPT vaccine, three doses of polio vaccine (excluding polio 0: polio vaccine given at time of birth), and a measles vaccination. Immunization was grouped into two categories: 0 (zero) if child had received all (BCG, three doses each of DPT and oral polio vaccine, and measles vaccine), and not immunized 1 (one) if the child missed any of the vaccinations.

Descriptive statistics such as frequencies and percentages were used to describe the socio-economic and demographic characteristics of the children in the study. Significant differences between the stunted and not stunted groups were determined using the chi-square test. Data were interpreted using a probability value of less than or equal to 0.05 to mean that a significant relationship or difference existed.

To identify other predictors of stunted growth, the study used multivariate regression. In the analysis, control was done for selected child, parent(s) and household characteristics. Control for these characteristics was done because they tend to be independently associated with children's health outcomes. The results of the multivariate analyses were presented as odds ratios (OR) with significance levels.

\section{Results and Discussion}

\subsection{Binary logistic regression analysis}

\subsubsection{Preliminary logistic regression models}

The author first ran preliminary regression models, of the different categories of explanatory variables against the outcome stunted growth. The different models were: Migrant characteristics in (Table 1), Child characteristics in (Table 2), and Household and Partner characteristics in (Table 3). The results were used to identify statistically significant predictors in each category, which were then introduced into the final Model (Table 4) to assess their combined effect on stunted growth.

\subsubsection{Stunted growth and migrant characteristics}

Table 1: Odds Ratios(OR) for the logistic regression model of Migrant Characteristics predicting stunted growth of children

\begin{tabular}{|c|c|c|c|c|}
\hline & \multirow{2}{*}{$\begin{array}{l}\text { Model1 } \\
\text { Migration } \\
\text { Status } \\
\text { OR } \\
\end{array}$} & \multicolumn{2}{|c|}{$\begin{array}{l}\text { Model 2 Model } 3 \\
\text { Migrant Characteristics }\end{array}$} & Model 4 \\
\hline & & OR & OR & $\mathrm{OR}$ \\
\hline $\begin{array}{l}\text { Mother : Migrant (Ref.) } \\
\text { Mother : Non-migrant } \\
\text { Skilled/Unskilled Employment } \\
\text { Employment Duration == All year (Ref.) }\end{array}$ & 0.917 & $\begin{array}{l}0.999 \\
1.846^{* * *}\end{array}$ & $\begin{array}{l}1.048 \\
0.938\end{array}$ & $\begin{array}{l}1.075 \\
0.938\end{array}$ \\
\hline Employment Duration $==$ Seasonal & & $1.235^{*}$ & 1.15 & 1.093 \\
\hline Employment Duration $==$ Occasional & & 1.346 & 1.294 & 1.266 \\
\hline \multicolumn{5}{|l|}{ Mother's Education $==$ none (Ref.) } \\
\hline Mother's Education == primary & & & 0.953 & 0.97 \\
\hline Mother's Education $==$ secondary & & & $0.516^{* * *}$ & $0.568 * * *$ \\
\hline Mother's Education == higher & & & $0.201 * * *$ & $0.246^{* * *}$ \\
\hline Exposure to Media & & & $1.385^{*}$ & $1.355^{*}$ \\
\hline \multicolumn{5}{|l|}{ Marital Status == Never married (Ref.) } \\
\hline Marital Status $==$ Formerly married & & & 1.447 & 1.498 \\
\hline Marital Status $==$ Currently married & & & 1.313 & 1.385 \\
\hline \multicolumn{5}{|l|}{ Mother's BMI $==18.5-24.9$ (Ref.) } \\
\hline Mother's BMI $==25+$ & & & & 0.834 \\
\hline Mother's BMI $==<18.5$ & & & & $0.526^{* * *}$ \\
\hline Constant & $0.441 * * *$ & $0.220^{* * *}$ & $0.297 * * *$ & $0.358^{* *}$ \\
\hline -2 Log Likelihood & -1836.49 & -1819.37 & -1773.43 & -1719.45 \\
\hline Model Chi-square & 1.162 & 26.719 & 110.615 & 127.405 \\
\hline Degrees of Freedom & 1 & 4 & 10 & 12 \\
\hline $\mathrm{N}$ & 3015 & 3010 & 3006 & 2928 \\
\hline
\end{tabular}

Source: Kenya Demographic and Health Surveys (KDHS), 2003 
The results in Model 4 (Table 1) show that the children of non-migrants have a 7\% greater chance of being stunted $(\mathrm{OR}=1.075)$ as compared to the children of migrants. The observed results are not statistically significant (p-value $>0.05$ ), and may be due to chance alone. The Model 4 results also showed increasing migrant's level of education and lower body Mass Index (BMI) to be protective against stunted growth in children.

\subsubsection{Stunted growth and child characteristics}

Table 2: Odds ratios (OR) for the logistic regression model of child characteristics predicting stunted growth of children

\begin{tabular}{|c|c|c|c|c|}
\hline & \multirow{2}{*}{$\begin{array}{l}\text { Model } 1 \\
\text { Migration } \\
\text { Status } \\
\text { OR }\end{array}$} & \multicolumn{2}{|c|}{$\begin{array}{l}\text { Model } 2 \text { Model } 3 \\
\text { Child Characteristics }\end{array}$} & Model 4 \\
\hline & & OR & OR & OR \\
\hline \multicolumn{5}{|l|}{ Mother : Migrant (Ref.) } \\
\hline Mother : Non-migrant & 0.917 & 0.876 & 0.855 & 0.85 \\
\hline \multicolumn{5}{|c|}{ Child's age $<12$ months (Ref.) } \\
\hline Child's age: $24-35$ months & & $4.548 * * *$ & $1.431 * * *$ & $1.441 * * *$ \\
\hline Child's age: $36+$ months & & $3.157 * * *$ & & \\
\hline \multicolumn{5}{|l|}{ Size at birth: Small (Ref.) } \\
\hline Size at birth: Average & & $0.638 * * *$ & $0.714 * *$ & $0.700 * *$ \\
\hline Size at birth: Large & & $0.525 * * *$ & $0.585^{* * *}$ & $0.563^{* * *}$ \\
\hline Complete Immunization & & & $0.756^{* *}$ & $0.748 * * *$ \\
\hline Sex of child & & & & $0.749 * * *$ \\
\hline Constant & $0.441 * * *$ & $0.223 * * *$ & $0.761 *$ & 1.203 \\
\hline -2 Log Likelihood & -1836.49 & -1743.91 & -1513.43 & -1507.99 \\
\hline Model Chi-square & 1.162 & 177.229 & 46.611 & 57.5 \\
\hline Degrees of Freedom & 1 & 5 & 5 & 6 \\
\hline $\mathrm{N}$ & 3015 & 3007 & 2388 & 2388 \\
\hline
\end{tabular}

$* \mathrm{p}<0.05, * * \mathrm{p}<0.01, * * * \mathrm{p}<0.001$

Source: Kenya Demographic and Health Surveys (KDHS), 2003

The results of Model 4 (Table 2) show the child's age, sex, size at birth and immunization status to be statistically significant predictors of stunted growth in children of non-migrant parents as compared to children of migrant parents. The results suggest that average or large child's size at birth, being female and having received complete immunization are protective against stunted growth. The risk of stunted growth however increases with increasing child age.

\subsubsection{Stunted growth and household and partner characteristics}

Table 3: Odds ratios (OR) for the logistic regression model of household \& guardian characteristics predicting stunted growth of

\begin{tabular}{|c|c|c|c|c|}
\hline & \multirow{2}{*}{$\begin{array}{l}\text { Model } 1 \\
\text { Migration } \\
\text { Status } \\
\text { OR } \\
\end{array}$} & \multicolumn{2}{|c|}{$\begin{array}{lr}\text { Model 2 } & \text { Model 3 } \\
\text { Household Characteristics }\end{array}$} & \multirow{2}{*}{$\begin{array}{l}\text { Model } 4 \\
\text { Partner } \\
\text { OR }\end{array}$} \\
\hline & & OR & OR & \\
\hline \multicolumn{5}{|l|}{ Mother : Migrant (Ref.) } \\
\hline Mother : Non-migrant & 0.917 & 1.033 & 1.109 & 1.079 \\
\hline Rural/urban area & & 1.26 & $0.705 *$ & $0.685^{*}$ \\
\hline \multicolumn{5}{|l|}{ Province : Nairobi (Ref.) } \\
\hline Province : Central & & 1.575 & 1.248 & 1.315 \\
\hline Province : Coast & & $2.097 * *$ & 1.377 & 1.441 \\
\hline Province : Eastern & & $1.927 * *$ & 1.44 & 1.516 \\
\hline Province : Nyanza & & $1.595 *$ & 1.071 & 1.193 \\
\hline Province : Rift Valley & & $1.867 * *$ & 1.272 & 1.34 \\
\hline Province : Eastern & & $1.604 *$ & 1.009 & 1.089 \\
\hline Province : North Eastern & & 1.161 & 0.575 & 0.659 \\
\hline \multicolumn{5}{|l|}{ HH children 5 and under $==1$ (Ref.) } \\
\hline HH children 5 and under $==2-3$ & & $1.458 * * *$ & $1.346^{* * *}$ & $1.377 * * *$ \\
\hline $\mathrm{HH}$ children 5 and under $==4+$ & & 1.274 & 1.268 & 1.156 \\
\hline \multicolumn{5}{|l|}{ Household Wealth Index $==$ lowest (Ref.) } \\
\hline Household Wealth Index $==$ second & & & 0.797 & 0.863 \\
\hline Household Wealth Index $==$ middle & & & $0.768 *$ & 0.866 \\
\hline Household Wealth Index $==$ highest & & & $0.571 * * *$ & $0.657 * *$ \\
\hline Household Wealth Index $==$ fourth & & & $0.285 * * *$ & $0.420 * * *$ \\
\hline \multicolumn{5}{|l|}{ Partner's Education $==$ none (Ref.) } \\
\hline Partner's Education $==$ primary & & & & 1.235 \\
\hline
\end{tabular}




\begin{tabular}{|c|c|c|c|c|}
\hline Partner's Education $==$ secondary & & & & 0.84 \\
\hline Partner's Education $==$ higher & & & & $0.546^{*}$ \\
\hline Partner Skilled/ & & & & \\
\hline Unskilled employment & & & & 1.184 \\
\hline Constant & $0.441 * * *$ & $0.129 * * *$ & 0.791 & 0.605 \\
\hline -2 Log Likelihood & -1836.49 & -1810.29 & -1787.59 & -1644.54 \\
\hline Model Chi-square & 1.162 & 53.571 & 98.965 & 126.269 \\
\hline Degrees of Freedom & 1 & 11 & 15 & 19 \\
\hline $\mathrm{N}$ & 3015 & 3015 & 3015 & 2783 \\
\hline
\end{tabular}

$* \mathrm{p}<0.05, * * \mathrm{p}<0.01, * * * \mathrm{p}<0.001$

Source: Kenya Demographic and Health Surveys (KDHS), 2003

According to literature, demographic factors and economic factors related to the household in whose care the migrant's children are left may influence the children's access to food. Literature also suggests that the characteristics of the guardian/remaining partner may influence the migrant's children access to health-care. Model 4 (Table 3) shows the final model we obtain, after controlling for Household and partner characteristics. The results show increasing household wealth, number of children under 5, and the household's location, whether rural or urban, all have a significant effect on stunted growth in children of non-migrants as compared to children of migrant parents. Partner's or Guardian's level of education was also found to predict stunted growth in children.

\subsubsection{Final logistic regression model}

Table 4: Odds ratios (OR) for the logistic regression model of migrant, child, household \& guardian characteristics predicting stunted growth of children

\begin{tabular}{|c|c|c|c|c|}
\hline & $\begin{array}{l}\text { Model } 1 \\
\text { Migration } \\
\text { Status }\end{array}$ & $\begin{array}{l}\text { Model } 2 \\
\text { Migrant }\end{array}$ & $\begin{array}{l}\text { Model } 3 \\
\text { Child }\end{array}$ & $\begin{array}{l}\text { Model } 4 \\
\text { Household } \\
\text { \& Partner }\end{array}$ \\
\hline & OR & OR & OR & OR \\
\hline \multicolumn{5}{|l|}{ Mother : Migrant (Ref.) } \\
\hline Mother : Non-migrant & 0.917 & 1.078 & 1.026 & 1.054 \\
\hline \multicolumn{5}{|l|}{ Mother's Education == none (Ref.) } \\
\hline Mother's Education $==$ primary & & 0.934 & 1.052 & 0.9 \\
\hline Mother's Education $==$ secondary & & $0.542 * * *$ & $0.554 * * *$ & $0.607 *$ \\
\hline Mother's Education $==$ higher & & $0.238 * * *$ & $0.220 * * *$ & $0.355^{*}$ \\
\hline Exposure to Media & & $1.390 *$ & $1.463 * *$ & 1.169 \\
\hline \multicolumn{5}{|l|}{ Mother's BMI $==18.5-24.9$ (Ref.) } \\
\hline Mother's BMI $==25+$ & & 0.828 & 0.979 & 0.967 \\
\hline Mother's BMI $==<18.5$ & & $0.527 * * *$ & $0.566 * * *$ & $0.663^{*}$ \\
\hline \multicolumn{5}{|l|}{ Child's age: <12 months (Ref.) } \\
\hline Child's age: $24-35$ months & & & $1.480 * * *$ & $1.489 * * *$ \\
\hline \multicolumn{5}{|l|}{ Size at birth: Small (Ref.) } \\
\hline Size at birth: Average & & & $0.716^{* *}$ & $0.755^{*}$ \\
\hline Size at birth: Large & & & $0.558 * * *$ & $0.579 * * *$ \\
\hline Incomplete Immunization & & & $0.812 *$ & $0.812 *$ \\
\hline Sex of child & & & $0.730 * * *$ & $0.737 * *$ \\
\hline Rural/urban area & & & & 0.809 \\
\hline \multicolumn{5}{|l|}{ HH children 5 and under $==1$ (Ref.) } \\
\hline $\mathrm{HH}$ children 5 and under $==2-3$ & & & & $1.496 * * *$ \\
\hline HH children 5 and under $==4+$ & & & & 1.279 \\
\hline \multicolumn{5}{|c|}{ Household Wealth Index == lowest (Ref.) } \\
\hline Household Wealth Index $==$ second & & & & 0.836 \\
\hline Household Wealth Index $==$ middle & & & & 0.871 \\
\hline Household Wealth Index == highest & & & & 0.753 \\
\hline Household Wealth Index $==$ fourth & & & & $0.526^{* *}$ \\
\hline \multicolumn{5}{|l|}{ Partner's Education $==$ none (Ref.) } \\
\hline Partner's Education $==$ primary & & & & $1.686^{* *}$ \\
\hline Partner's Education $==$ secondary & & & & 1.184 \\
\hline Partner's Education $==$ higher & & & & 0.904 \\
\hline Constant & $0.441 * * *$ & $0.493 * * *$ & 1.017 & 1.224 \\
\hline
\end{tabular}




\begin{tabular}{lllll}
\hline-2 Log Likelihood & -1836.49 & -1726.38 & -1396.4 & -1299.44 \\
Model Chi-square & 1.162 & 122.229 & 186.455 & 205.833 \\
Degrees of Freedom & 1 & 7 & 12 & 22 \\
$\mathrm{~N}$ & 3015 & 2933 & 2313 & 2169 \\
\hline
\end{tabular}

${ }^{*} \mathrm{p}<0.05, * * \mathrm{p}<0.01, * * * \mathrm{p}<0.001$

Source: Kenya Demographic and Health Surveys (KDHS), 2003

Table 5: Odds Ratios (OR), probability values (P), and confidence intervals (CI) for the logistic regression model of migrant, child, household \& guardian characteristics predicting stunted growth of children

\begin{tabular}{|c|c|c|c|}
\hline & OR & $\mathbf{P}$ & $95 \% \mathrm{CI}$ \\
\hline \multicolumn{4}{|l|}{ Mother : Migrant (Ref.) } \\
\hline Mother : Non-migrant & 1.054 & $(0.591)$ & {$[0.869,1.279]$} \\
\hline \multicolumn{4}{|l|}{ Mother's Education == none (Ref.) } \\
\hline Mother's Education $==$ primary & 0.9 & $(0.545)$ & {$[0.638,1.267]$} \\
\hline Mother's Education $==$ secondary & 0.607 & $(0.021)^{*}$ & {$[0.397,0.927]$} \\
\hline Mother's Education $==$ higher & 0.355 & $(0.010)^{*}$ & {$[0.161,0.783]$} \\
\hline Exposure to Media & 1.169 & $(0.341)$ & {$[0.848,1.612]$} \\
\hline \multicolumn{4}{|l|}{ Mother's BMI $==18.5-24.9$ (Ref.) } \\
\hline Mother's BMI $==25+$ & 0.967 & $(0.818)$ & {$[0.727,1.286]$} \\
\hline Mother's BMI $==<18.5$ & 0.663 & $(0.025)^{*}$ & {$[0.463,0.949]$} \\
\hline \multicolumn{4}{|l|}{ Child's age: $<12$ months (Ref.) } \\
\hline Child's age: $24-35$ months & 1.489 & $(0.000)^{* * *}$ & {$[1.236,1.795]$} \\
\hline \multicolumn{4}{|l|}{ Size at birth: Small } \\
\hline Size at birth: Average & 0.755 & $(0.036)^{*}$ & {$[0.581,0.982]$} \\
\hline Size at birth: Large & 0.579 & $(0.000)^{* * *}$ & {$[0.430,0.781]$} \\
\hline Complete Immunization & 0.812 & $(0.031)^{*}$ & {$[0.672,0.982]$} \\
\hline Sex of child & 0.737 & $(0.001)^{* *}$ & {$[0.612,0.888]$} \\
\hline Rural/urban area & 0.809 & $(0.216)$ & {$[0.579,1.132]$} \\
\hline \multicolumn{4}{|l|}{ HH children 5 and under $==1$ (Ref.) } \\
\hline $\mathrm{HH}$ children 5 and under $==2-3$ & 1.496 & $(0.000)^{* * *}$ & {$[1.215,1.841]$} \\
\hline HH children 5 and under $==4+$ & 1.279 & $(0.332)$ & {$[0.778,2.102]$} \\
\hline \multicolumn{4}{|c|}{ Household Wealth Index == lowest (Ref.) } \\
\hline Household Wealth Index $==$ second & 0.836 & $(0.195)$ & {$[0.638,1.096]$} \\
\hline Household Wealth Index $==$ middle & 0.871 & $(0.326)$ & {$[0.661,1.147]$} \\
\hline Household Wealth Index $==$ highest & 0.753 & $(0.079)$ & {$[0.549,1.033]$} \\
\hline Household Wealth Index $==$ fourth & 0.526 & $(0.006)^{* *}$ & {$[0.333,0.832]$} \\
\hline \multicolumn{4}{|l|}{ Partner's Education == none (Ref.) } \\
\hline Partner's Education $==$ primary & 1.686 & $(0.010)^{* *}$ & {$[1.134,2.506]$} \\
\hline Partner's Education $==$ secondary & 1.184 & $(0.447)$ & {$[0.766,1.829]$} \\
\hline Partner's Education $==$ higher & 0.904 & $(0.739)$ & {$[0.498,1.641]$} \\
\hline Constant & 1.224 & $(0.667)$ & {$[0.487,3.074]$} \\
\hline-2 Log Likelihood & -1299.44 & & \\
\hline Model Chi-square & 205.833 & & \\
\hline Degrees of Freedom & 22 & & \\
\hline $\mathrm{N}$ & 2169 & & \\
\hline
\end{tabular}

Source: Kenya Demographic and Health Surveys (KDHS), 2003

The results of the study showed no evidence of association between parent's migration status and nutritional outcomes of the under five year old children of migrant parents.

The migration status variable was first entered into Model 1 (Table 5), while using the children of migrant parents as the reference category, based on the theoretical perspective that migration improves nutritional outcomes in children therefore reduces the chance of observing stunted growth in these children. The results in Model 1 (Table 5) show that the children of non-migrant parents were 19 per cent less likely to be 
stunted (though not statistically significantly) as compared to those of migrants, before controlling for other factors. The results in Model 1 fail to support the hypothesis that parent migration is significantly related to reduced stunted growth in children.

\section{Conclusion and Recommendations}

From the study findings, it is evident that household factors, both the size of income, measured by household wealth index, and the size of the household measured by the number of under 5 year olds in the household is associated with stunted growth in children. Increased incomes protect against stunted growth, while increasing household size increases risk of stunted growth. These results are different from findings in Ghana [24], which showed no association between improved migrant remittances, household incomes and better access to food and healthcare, they however tally with findings in Kenya [14], which showed increasing household size to impact negatively on a household's benefits due to migrant remittances.

It is also clear that increased education of women is associated with a reduced risk of stunted growth in children. These results are similar to findings from a cross-country study, which found maternal education to be associated with complete immunization in children [21], where complete immunization was used as a measure of child health. Contrary to results that suggest poor health outcomes are likely to be observed in children whose mothers are of poor health [8], it was established that children of underweight mother's are less likely to be stunted as compared to children whose mothers are of normal weight. These results are likely to be true, since in the study, underweight mothers constitute only $13 \%$ of the sample, whereas the reference category, mothers of normal weight, constitute $70 \%$ of the sample. If one considers the intergenerational component of malnutrition in female children, the observed results suggest that the children's mothers may have suffered malnutrition as children. The observed results therefore may be explained by the psychological theory that parents try to provide for their children what they themselves lacked while growing up.

In conclusion, the results of the study show the need for programme evaluators to: develop an understanding of the multiple causative factors of a public health problem; prepare and document a detailed conceptual framework, and evaluate programmes using both program-level and population-based indicators. This is because the study findings demonstrate that problems such as child malnutrition are a result of several immediate, underlying and basic causes. Where the evaluator wants to empirically demonstrate the impact of a programme, he must during analysis, control for these confounding factors, before he can attribute an observed change in health outcomes to the program intervention.

\section{References}

[1]. A. Whitehead, and I. Hashim, Children and Migration, Background paper for the DFID Migration Team. Department for International Development (DFID). 2005 March. Available at: http://www.dfid.gov.uk/wp2005/default-old.asp. Accessed on 21 ${ }^{\text {st }}$ September 2008.

[2]. Department for International Development (DFID), The 2007 White Paper on Migration. Moving out of poverty making migration work better for poor people. 2007 March. Available at http://www.dfid.gov.uk/pubs/files/migration-policy.pdf. Accessed on 20 th June 2008

[3]. Lu Yao, and D. J. Treiman, The Effect of Labor Migration and Remittances on Children's Education among Blacks in South Africa. On-Line Working Paper Series \#CCPR-001-07. Los Angeles. California Center for Population Research, University of California. 2007 January.

[4]. K. Randall, The Effects of Father's and Sibling's Migration on Children's Pace of Schooling in Rural Bangladesh, Asian Population Studies, 2(1), 2006, 69-92.

[5]. J. Nobles, Parental Migration and Child Health in Mexico California Center for Population Research, University of California, Los Angeles. Available at: http://jnobles.bol.ucla.edu/papers.htm accessed on $29^{\text {th }}$ August, 2007

[6]. N. Hildebrandt, and D. J. McKenzie, The Effects of Migration on Child Health in Mexico. Policy Research Working Paper \#3573 (Washington D.C.: World Bank, 2005).

[7]. World Health Organization, A WHO report on inequities in maternal and child health in Mozambique (Geneva: World Health Organization, 2007).

[8]. UNICEF, Strategy for Improved Nutrition of Children and Women in Developing Countries, (New York: UNICEF). Policy Review Paper E/ICEF/1990/1.6. 1990

[9]. D. Pelletier, The relationship between Child Anthropometry and Mortality in Developing Countries. Implications for Policy, Programs and Future Research (2047S). Supplement to Journal of Nutrition, 124, 1994, 10S.

[10]. M. McCarthy, Urban development and health inequalities, Scandinavian Journal of Public Health, 30(3), 2002, 59-62.

[11]. D. L. Pelletier, E. A. Frongillo, D. G. Schroeder, J. P. Habicht, The effects of malnutrition on child mortality in developing countries. Bulletin of the World Health Organization, 73, 1995, 443-448.

[12]. UNICEF, Report on Child Malnutrition (New York, 2002). URL: http://www. unicef.org/specialsession/about/sgreport,pdf/02_Child Malnutrition_D7341Insert_English.pdf. Accessed on 03 October 2007

[13]. Central Bureau of Statistics, Measure DHS+. Kenya Demographic and Health Survey (Full Report (Nairobi: Central Bureau of Statistics, 2003).

[14]. R. U. Agesa, and S. Kim, Rural to Urban Migration as a Household Decision Evidence from Kenya Review of Development Economics, 5(1), 2001, 60-75.

[15]. K. Macours, and R. V. Vakis, Seasonal Migration and Early Childhood Development. SP Discussion Papers. 2007 March.

[16]. R. Ssengozi, G. F. De Jong, and C. S. Stokes, The effect of female migration on Infant and child survival in Uganda. Population Research and Policy Review, 21, 2002, 403-431. 
[17]. V. Mishra, F. Arnold, F. Otieno et al. Education and Nutritional Status of Orphans and Children of HIV-Infected Parents in Kenya. DHS Working Papers. 2005 August.

[18]. K. A. Lindblade, F. Odhiambo, D. H. Rosen, and M. K. DeCock, Health and nutritional status of orphans $<6$ years old cared for by relatives in western Kenya. Tropical Medicine and International Health (2003 January) 8(1), 67-72.

[19]. S. Malabika, N. Christina, and M. Olaf, Assessing the health status of young AIDS and other orphans in Kampala, Uganda. Tropical Medicine and International Health, 10(3), 2005 March, 210-215.

[20]. P. R. Pahnde, Selective Gender differences in Childhood nutrition and immunization in rural India : The role of siblings. Journal of Demography, 40(3), 2003 August, 395-418.

[21]. S. Desai, and S. Alva, Maternal Education and Child Health: Is There a Strong Causal Relationship? Demography, 35(1), 1998 February, 71-81.

[22]. M. J. Dibley, J. B. Goldsby, N. W. Staehling, and F. L. Trowbridge, Development of normalized curves for the international growth reference: Historical and technical considerations. American Journal of Clinical Nutrition, 46, 1987, 736-48.

[23]. M. J. Dibley, N. W. Staehling, P. Neiburg, and F. L. Trowbridge. Interpretation of z-score anthropometric indicators derived from the international growth reference. American Journal of Clinical Nutrition, 46, 1987, 749-62.

[24]. R. H. Adams, Jr., A. Cuecuecha, and J. Page, Remittances, Consumption and Investment in Ghana. Policy Research Working Paper Series 4515 (The World Bank, 2006). 